\title{
Effect of Big Data Era on Accounting Practitioners and Possible Countermeasures
}

\author{
Chen Shuyi ${ }^{1, a}$ \\ ${ }^{1}$ Hohai University School of Business Administration, 200 Jinling North Road, Xinbei District, \\ Changzhou, Jiangsu, China \\ a1343168702@qq.com
}

Keywords: Big Data, Accounting, Excellence, Impact, Measures

\begin{abstract}
Big data has been sweeping all industries since its emergence, accounting is, of course, no exception. As accountants, we are now facing both unprecedented opportunities and unimaginable challenges, among which how to improve ourselves and keep up with big data era has become a common concern. Aiming at evoking more practitioners to upgrade qualities and professional proficiency, thus fostering themselves into more outstanding accountants that meet the needs of social developments and create more value for enterprises, this paper is developed as follows: first the discussions on the definition of big data, then the analysis of its impacts on accountants in terms of four aspects, at last, three suggestions are given out for your information.
\end{abstract}

\section{Introduction}

With the extensive application of Internet technology, the rapid development of information processing technology and the speed of data processing and analysis, the advent of the era of big data has improved business development and innovation. At the same time, big data also brings new opportunities and challenges to traditional accounting practitioners. Under the current situation that the traditional financial work mode gradually can not meet the needs of the long-term development of enterprises, accounting should tightly integrate with big data.

\section{Brief Introduction of "Big Data"}

Big data, also known as mass data, refers to data collection that cannot be captured, managed and processed by conventional tools within an affordable time range. Only through new processing mode can we develop it into highly diversified and fast-growing information assets featured by stronger decision power, deeper insight and better optimization capability. The strategic significance of big data technology lies not in obtaining huge amount of information, but in specialized processing of these meaningful data. Generally speaking, big data has characteristics as follows:

First, big data is numerous and jumbled. It takes in various forms and enjoys rapid growth rates. Massive amount is a major difference that distinguishes big data era from the one of small data, for example, the data processed by Google everyday surpass thousands of times the data of all printed publications held in the National Library of America. Data forms vary from video, audio, picture, to web pages and other formats, of which the methods of storage and management, as well as functions are not the same, presenting relatively greater complexity.

Second, the density and value of data depend on development level. The value of big data is decided by purpose and utilization, while efficiency and results of development are directly affected by statistical acumen and thinking modes' sharpness.

Third, big data is inexhaustible. Big data's reuse value increases as its development round accumulates. Every perspective into it can lead to amazing researches, and research networks can be expanded through recombination, extension, and clustering of existing studies. Through continuous exploration, big data releases more and more energy, unlike material resources. 


\section{Influences of Big Data on the Definition of "Excellence"}

Big data has brought about epoch-making changes in accounting. It subverted traditional development thinking modes and concepts of the industry, strongly influencing accounting practitioners, as shown in four aspects below.

Firstly, traditional functions of accounting practices are undergoing weakening. At the center of functions are accounting function and supervision function. Accounting describes the conducts by accountants including bookkeeping, balancing and reporting of enterprises' economic behaviors, as well as proving accounting information for managers, tax authorities, banks and other parties concerned. As for supervision, it refers to the examination of authenticity, legality and rationality of enterprises' economic behaviors, through which the enterprises operate according to the laws and regulations can be ensured. At present, China has 30 million accounting practitioners, most of them engaged in accounting and supervision. But in the era of big data, manual enterprise accounting work will be gradually replaced by artificial intelligence in the future as it develops. It is reported that Deloitte has introduced a financial robot to take charge of accounting routines for enterprises. Once widely used, financial robots will have a major impact on accounting profession, and those who can only conduct accounting works will be sifted out.

What's more, management accounting will be more valuable. Previously, accountants used data analyses to help with managers' decisions. Based on statements, those analyses can only provide limited information. While in the era of big data, enterprises are embracing wider ranges of data and more complete cause chains underlying, through which practitioners can have a more comprehensive recognition of enterprises' current situation and problems, and assess timely their financial status and operation performance, so as to reveal problems existing in business activities and provide improvement clues for them. With the help of big data technology, practitioners can effectively enhance financial management level, reduce capital costs and create rich profits for enterprises, bringing their talents into full play.

Third, data processing ability becomes a must. For accountants, big data offers both opportunities and challenges. It not only creates a better environment for them to contribute strong data support to enterprise decision-making through scientific classification, sorting and analysis of data but also puts forward requests on them to develop information integration, data mining and analysis abilities. We can see that in the future, competences of data collection, analysis, induction and utilization will become necessary qualities for accounting practitioners.

Fourth, accountants will have to expand their knowledge scopes. In the era of big data, practitioners are dealing with financial and non-financial data, structured and unstructured ones, as well as internal and external ones--the former involves budget control, cost management, risk analysis and credit management, while the latter extends to macro policies, market information and customer preferences. To analyze and transform these data into valuable information for enterprises that serve decision-making, practitioners must have a broader vision, larger knowledge reserves, and deeper thinking, analysis and summary into phenomena. Otherwise, they cannot be qualified for their positions.

\section{Possible Countermeasures for Practitioners to be More Outstanding in the Era Of Big Data}

To improve professional competence and provide enterprises with more valuable services, future accounting practitioners must exert themselves in aspects follows:

To begin with, importance should be attached to the study of accounting and relevant professional knowledge. A solid foundation of professional knowledge is the prerequisite of performing duties well. Despite the trend that accounting will be replaced by artificial intelligence one day, professional literacy will remain significant as it is always the basis of assessment and selection of accounting methods and strategies for the good of business. That is to say, practitioners should spare no efforts to strengthen fundamental knowledge, get a good command of accounting principles and financial management index, etc., and be flexible in their application. Investment and finance-related knowledge should also be stressed for better services for enterprises' decisions in 
corresponding fields. Besides, learning tax law helps with offering suggestions for reasonable tax avoidance, comprehension of economic laws and regulations such as contract law contributes to risk prevention, and knowledge about macroeconomics, microeconomics, marketing broadens our horizons so that we can provide more valuable services for management.

Secondly, we must be proficient in relevant data processing skills. To cope with large amount of data that in complicated structures, differentiated qualities and diversified forms, accounting practitioners should be capable of data collecting, sorting, summarizing, classifying as well as utilizing. To achieve that goal, practitioners should first be familiar with basic computer skills and accustomed to use office software to carry out data processing assignments. Besides, database knowledge is also necessary, through skillful utilization of databases such as Oracle, further works including collation, transformation and analysis can be accomplished. Last but not least, we should learn to distinguish data quality, with enterprises' operation objectives at the center, we should purposefully screen and filter, discard the dross and select the essential of information, finally dig out valuable data for enterprises.

Thirdly, bigger data practices that serve enterprise management should be put on agenda. The best ideas and thoughts must be tested by practice to know the actual effect. Therefore, as an accountant, we must continuously strengthen the use of big data to serve the management practice of enterprises. To start with, we should integrate internal data, establish accounting information data center, establish operating standards and technical standards, through unification of primary data forms and integration of data scattered in various departments, finally develop a data system that is systematic, complete, highly-efficient and consistent. We can streamline the whole process of accounting, standardize all steps from the acquisition of original vouchers to the compiling of accounting documents, to ledgers recording and cost accounting, and the generation of accounting reports. In this way, transparency and effectiveness of supervision can be greatly improved while information processing cost of enterprises reduced. Furthermore, through continuous clustering and reorganizing, we can implement reconstruction methods to excavate the great value hidden inside, so as to provide more references and feasible suggestions for decision-making. On the other hand, equal stress should be laid on collecting external information related to enterprise development, including industry landscape, customer credit, macro policy and economic trend, thus associating big data with the company's development goals, refining large amount of information into precise insights, and providing more valuable services for enterprises.

\section{Conclusion}

In summary, accounting practitioners must be able to apply the opportunities brought by big data properly, develop effective and positive measures to meet the challenges faced by enterprises. To make accounting practitioners more adapt to the needs of the modern era, serve for business operation, decision-making and management better, importance should be attached to the study of accounting and relevant professional knowledge, the proficient in relevant data processing skills and more big data practices that serve enterprise management should be put on agenda.

\section{References}

[1] Sheng Yang, Zhou Tao. The era of big data [M]. Zhejiang People's Publishing House, 2013.1

[2] Tian Yan. "Big Data" to lead intelligent financial management [J]. Shanxi University of Finance and Economics, 2018, 40 (z2).

[3] Li Ming, Wang Jialin, Li Ying. Research on Key Influencing Factors of Accounting Information Risk in Big Data Era[J]. Chinese Certified Public Accountant, 2018.

[4] Corporate financial restructuring under Wang Bo think the era of big data $[\mathrm{J}]$ new accounting, 2017 (11): 49-50.

[5] Pi Ailan. Challenges and Changes of Enterprise Financial Management under the Background of Big Data[J]. Accounting Learning, 2018, No.178(04):44-45. 
[6] Sun Mengyang. Research on Enterprise Financial Management Information Construction in Big Data Era[J]. Modern Economic Information, 2018(14):185+187.

[7] Cheng Ping, Zhao Zixiao. Analysis of the Influence of Big Data on Enterprise Financial Decisions[J]. Finance and Accounting, 2014(10): 49-50.

[8] Xue Ru. Research on the Impact of Big Data on Corporate Financial Decisions[J]. Times Economics and Trade, 2015(11).

[9] Wei Jianhua. Research on Enterprise Financial Decisions in the Age of Big Data and Cloud Accounting[J]. Accounting, 2018, 207(33): 38-39.

[10] Kang Yuxia, He Xiaoli. Research on Accounting Occupational Risk in the Age of Big Data[J]. Economic Research Reference, 2018, 2895(47): 91-94. 